\title{
Supply Source Location Involving Fixed Charges And Economics Of Scale: A Heuristic Approach
}

\section{STEPHEN FULLER}

This paper presents a model capable of accommodating plant location problems where 1) the long-run source or plant cost function exhibits a positive intercept (fixed charge), 2) the long-run plant cost function is discontinuous, and 3) there are economies of scale associated with increasing plant size. The model developed and presented here reverses the cost minimizing sequence of the Chern and Polopolus formulation, a model designed to include a discontinuous long-run plant cost function. For many types of plant location problems, the developed model (source location cost-sequencing model) will yield a lower cost solution than the Chern and Polopolus formulation.

The discontinuous plant cost function argument centers on the indivisibility of durable equipment available to construct alternative source sizes. ${ }^{1}$ Because technology for constructing alternative plant sizes is restricted, a limited number of short-run plant cost functions may exist. Therefore, a specified source size may be applicable over a wide range of output. In which case, the long-run source cost function is discontinuous. See Figure 1.

*Associate Professor, Department of Agricultural Economics, Texas A\&M University.

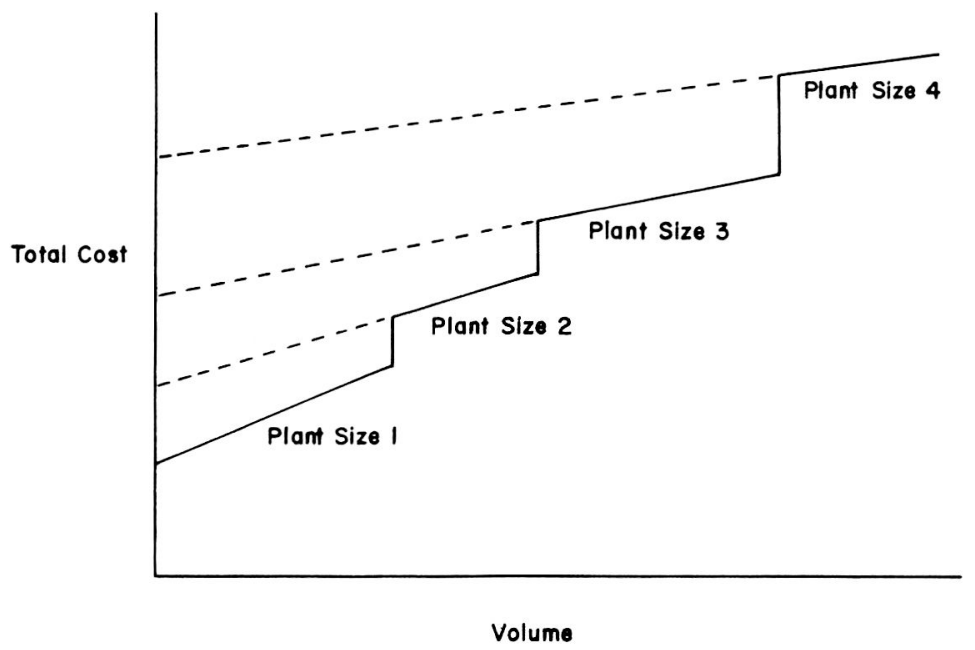

Figure 1. Discontinuous Plant Cost Function 
The model presented here is adapted to include several plant cost structures. In particular, each plant's short-run total cost function may have a unique positive intercept and unit cost value, or each short-run function may possess a unique intercept value but have unit costs which are analogous to other functions. Figure 1 is representative of that plant cost structure where each plant size's intercept and unit cost value are unique.

This paper proceeds with 1) a mathematical statement of the source location problem, 2) a mathematical statement of the developed source location cost-sequencing model and a comparison with the Chern and Polopolus model, 3) a small-scale numerical example involving comparisons of the Chern and Polopolus model with the source location cost-sequencing model and 4) an application of the source location costsequencing model.

\section{A Mathematical Statement of the Problem}

Given are $M$ destinations with known levels of demand, $D_{1}, D_{2}, \ldots$, $\mathrm{D}_{\mathrm{M}}$. The destinations are numbered, $\mathrm{j}=1,2, \ldots, \mathrm{M}$. There are $\mathrm{N}$ potential source locations, numbered $\mathrm{i}=1,2, \ldots, \mathrm{N}$, and $\mathrm{P}$ source sizes, numbered $\mathrm{k}=1,2 \ldots$. . P. Each of the $\mathrm{P}$ source cost functions (segments of the long-run cost function) has an annual fixed charge $\left(f_{k}\right)$ and displays constant marginal costs $\left(c_{k}\right) .{ }^{2}$ Annual capacity for each of the $\mathrm{P}$ sources is known and is represented by $R_{k}$. In addition, economies of scale exist. Distribution costs between each pair of potential source locations and destinations are proportional to the quantity distributed and the distance between the pair of points. Unit distribution cost from the ith potential source location to the jth destination is represented by $t_{i j}$, while $X_{i j}$ denotes quantity of commodity or service transported from the ith source location to the jth destination.

The objective is to determine the number, size and location of sources which minimize total plant and distribution costs; namely, minimize:

$$
\underset{\mathrm{k}=\mathrm{l}}{\mathrm{P}} \underset{\mathrm{i}=\mathrm{l}}{\sum_{\mathrm{k}=\mathrm{l}}^{\mathrm{N}}} \mathrm{f}_{\mathrm{k}} \mathrm{y}_{\mathrm{ki}} \underset{\mathrm{i}=\mathrm{l}}{\sum_{\mathrm{j}=-\mathrm{l}}^{\mathrm{P}}} \underset{\mathrm{N}}{\mathrm{N}} \underset{\mathrm{N}}{\mathrm{M}}\left(\mathrm{c}_{\mathrm{k}}+\mathrm{t}_{\mathrm{ij}}\right) \mathrm{X}_{\mathrm{ij}}
$$

where,

$$
\begin{aligned}
& \mathrm{y}_{\mathrm{ki}}=1 \text { if source size } \mathrm{k} \text { is located at } \mathrm{i} \\
& \mathrm{y}_{\mathrm{ki}}=0 \text { if no source size } \mathrm{k} \text { is located at } \mathrm{i}
\end{aligned} \text { for } \mathrm{i}=1,2, \ldots, \mathrm{N} .
$$

An admissible solution must be one where source capacity is capable of meeting aggregate demands; namely,

$$
\underset{\mathrm{k}=-\mathrm{l}}{\mathrm{P}} \underset{\mathrm{i}=\mathrm{l}}{\sum} \mathrm{R}_{\mathrm{k} \mathrm{y}_{\mathrm{ki}} \geq}^{\mathrm{N}} \underset{\mathrm{j=l}}{\sum_{1}^{\mathrm{M}}} \mathrm{D}_{\mathrm{j}}
$$


Also, the $\mathrm{X}_{\mathrm{ij}}$ and $\mathrm{y}_{\mathrm{ki}}$ variables are related in a conditional manner. If no source is located at location $\mathrm{i},{\underset{\mathrm{k}}{\mathrm{N}} \mathrm{P}}_{\mathrm{ki}}^{\mathrm{P}}=0$, in which case, $\mathrm{X}_{\mathrm{ij}}=0$ for that location. Only if $\underset{\mathrm{k}=1}{\mathrm{P}} \mathrm{y}_{\mathrm{ki}}==1$, can $\mathrm{X}_{\mathrm{ij}}$ be non-zero; this gives the set of conditional restraints.

$$
\left.\begin{array}{l}
\mathrm{X}_{\mathrm{ij}}=0 \text { if } \sum_{\mathrm{k}=1}^{\mathrm{P}} \mathrm{y}_{\mathrm{ki}}=0 \\
\mathrm{X}_{\mathrm{ij}}>0 \text { if } \sum_{\mathrm{k}=1}^{\mathrm{P}} \mathrm{y}_{\mathrm{ki}}=1
\end{array}\right\} \text { For } \mathrm{i}=1,2, \ldots, \mathrm{N} \text { and all for all values of } \mathrm{j} .
$$

\section{A Comparison of the Chern and Polopolus Model}

\section{With the Developed Source Location Cost-Sequencing Model}

'The plant location problem involving the discontinuous cost function may be formulated as a mixed integer programming problem. However, the discontinuous plant cost function magnifies the computational burden of obtaining a solution because of the need to consider all plant size combinations. Mixed integer programming systems available from leading computer manufacturers are the most capable of existing $\operatorname{codes}^{3}$ but, in general, become computationally expensive for problems involving in excess of one-hundred variables. In which case, only very small location problems of the discontinuous plant cost function type can be solved efficiently, given existing mixed integer code capabilities. Therefore, heuristic techniques are necessary.

The heuristic procedure by Chern and Polopolus involves two steps [3]. The initial step involves a determination of the least-cost locational configurations; that is, the allocation of commodity or service at plant locations which minimizes total distribution cost for each subset, $n$, of the $\mathrm{N}$ source locations, where $\mathrm{n}<\mathrm{N}$. Second, the total distribution and source cost with respect to number of locations, number of sources and source size pattern is minimized. This is accomplished by first determining source numbers and corresponding source sizes which minimize total source cost for each location within each of the $\mathrm{n}$ subset's optimum locational configuration. After least-cost source number and size patterns within each of the $n$ subset's optimal locational pattern has been determined, source costs are aggregated. This procedure is repeated for each of the $\mathrm{n}$ subsets. The overall optimum is determined by aggregating minimized distribution and source cost for each of the $n$ subsets and then identifying the minimum.

The Chern and Polopolus model answers two sequenced questions. They are: 1) what allocation of commodity or service minimizes distribution cost for each of the $\mathrm{n}$ subsets of considered source locations, and 
2) what source size pattern minimizes industry aggregated source cost for each of the $n$ subsets optimum locational configuration. The model developed in this paper answers the following questions sequentially: 1) which source size pattern for each of the $n$ subsets of source locations minimizes total source cost, and 2) which locational configuration for each of the n subset's optimum source size pattern minimizes total distribution cost. By reversing the steps in which distribution and source costs are optimized, cost emphasis is reversed.

The developed source location cost-sequencing model approximates an overall minimum by accomplishing the following three steps:

Step 1. For each $\mathrm{n}$, select that source size pattern which minimizes total source cost (TPC); namely, minimize the following function:

$$
\mathrm{TPC}=\sum_{\mathrm{k}=\mathrm{l}}^{\mathrm{P}} \underset{\mathrm{i}=\mathrm{l}}{\mathrm{N}} \mathrm{f}_{\mathrm{k}} \mathrm{y}_{\mathrm{ki}}+\underset{\mathrm{k}=\mathrm{l}}{\mathrm{P}} \underset{\mathrm{i}=\mathrm{l}}{\sum} \underset{\mathrm{j}=\mathrm{l}}{\mathrm{N}} c_{\mathrm{k}} \mathrm{X}_{\mathrm{ij}}
$$

and denote the resulting minima for each $\mathrm{n}$.

Step 2. Using the least-cost source size pattern for each $\mathrm{n}$, determined in Step 1, find those locations which minimize total distribution cost (TAC) . ${ }^{4}$ Minimize for each $\mathrm{n}$ :

$$
\mathrm{TAC}=\sum_{\mathrm{i}=1}^{\mathrm{N}} \underset{\mathrm{j}=1}{\mathrm{M}} \mathrm{t}_{\mathrm{ij}} \mathrm{X}_{\mathrm{ij}}
$$

Step 3. Using the results for each value of $\mathrm{n}$ found in Steps 1 and 2, find that value of $\mathrm{n}$ which minimizes total system cost (TC); namely, minimize:

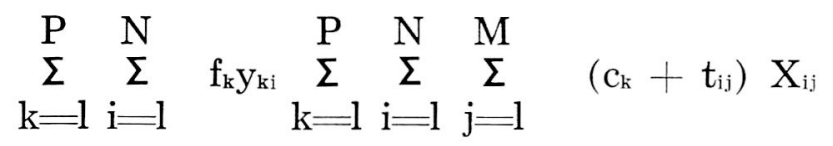

Minimization of the total source cost function (TPC, Step 1) is accomplished by an algorithm which calculates cost for all source combinations for each of the $n$ subsets of source locations. ${ }^{5}$ After calculations of each n's least-cost source size pattern, a fast transportation code developed by Srinivasan is employed to calculate total distribution costs associated with allocating these facilities between alternative locations. ${ }^{6}$ That location configuration which minimizes total distribution cost for each of the $\mathrm{n}$ subsets constitutes the minimized total distribution cost function (TAC, Step 2). The least-cost subset is determined by summing the minimized source (Step 1) and distribution cost function for each of the n subsets.

A priori reasoning permits insight into the bias associated with the above heuristic solution techniques. The sequence in which costs are minimized imparts a bias into the solution. The cost initially optimized 
is given priority since the second stage of optimization is forced to accommodate the first stage decision. When using the source location costsequencing model, the commodity or service is allocated to accommodate the optimum source size pattern that is resolved in the first step. The second step involves location of this optimum source size pattern so as to minimize distribution cost. In contrast, the Chern and Polopolus model initially optimizes with respect to distribution or transportation cost; then, in the second stage it seeks that source size pattern to optimally accommodate the initial stage's outcome. Clearly, the solution rendered by the source location cost-sequencing model will have lower plant or source costs but larger distribution costs than the Chern and Polopolus model. Or, vice versa, the Chern and Polopolus formulation will yield lower distribution costs but larger plant costs than the source location cost-sequencing model. The appropriate model depends on the specific characteristics of the source location problem. Generally, if 1) unit distribution cost is small relative to unit plant cost, 2) demand nodes are not highly dispersed and 3 ) there are substantial economies associated with larger plants, then the source location cost-sequencing technique is most appropriate. If the opposite situation prevails, then the Chern and Polopolus model may yield lower costs.

\section{Numerical Example}

Suppose there are three market locations or destinations $(\mathrm{M}=3)$ which have annual demands $\left(\mathrm{D}_{1}, \mathrm{D}_{2}, \mathrm{D}_{3}\right)$ of 3,6 and 3 units, respectively. In addition, there are three potential source locations $(\mathrm{N}=3)$ and two source sizes $(P=2)$. Suppose that the annual fixed charge $\left(f_{1}\right)$ for the small source (size 1 ) is $\$ 2$, unit source cost $\left(c_{1}\right)$ is $\$ 1$ and the source has capacity $\left(R_{1}\right)$ to provide 4 units annually. The fixed charge $\left(f_{2}\right)$ for the large source (size 2) is $\$ 3$, unit source cost $\left(c_{2}\right)$ is $\$ .75$ and the source has capacity $\left(R_{2}\right)$ to provide 6 units annually. Unit distribution cost, $t_{\mathrm{ij}}$, from the three potential source locations to the three demand locations is given by the following matrix:

\begin{tabular}{cccc} 
& $\begin{array}{c}\text { Demand } \\
\text { Location } \\
1\end{array}$ & $\begin{array}{c}\text { Demand } \\
\text { Location } \\
2\end{array}$ & $\begin{array}{c}\text { Demand } \\
\text { Location } \\
3\end{array}$ \\
\cline { 2 - 4 } $\begin{array}{c}\$ \\
\begin{array}{c}\text { Potential source } \\
\text { Location 1 }\end{array}\end{array}$ & .20 & .40 & $\$$ \\
$\begin{array}{c}\text { Potential source } \\
\text { Location 2 }\end{array}$ & .10 & .10 & .30 \\
$\begin{array}{c}\text { Potential source } \\
\text { Location 3 }\end{array}$ & .30 & .20 & .35 \\
\hline
\end{tabular}

This small problem can be solved through complete enumeration of all combinations. For the discontinuous plant location problem, the total number of combinations can be represented by $(\mathrm{P}+1) \mathrm{N}-1$ where 
$\mathrm{P}$ represents the number of plant sizes comprising the long-run function and $\mathrm{N}$ equals potential source locations. Consequently, there are 26 combinations $\left[(2+1)^{3}-1=26\right]$ involving the 2 plant sizes at the 3 potential source locations; however, only 11 combinations have sufficient capacity to meet the 12 units of demand. Those source size combinations with sufficient capacity to meet demands are shown at all possible source locations in Table 1 . The combination $(1,1,2)$ indicates that source size 1 is located at source locations 1 and 2 , while source size 2 is located at source location 3 . Whereas, combination $(2,0,2)$ denotes placement of source size 2 at source locations 1 and 3 . The 0 indicates that no source is located at source location 2. The fixed source costs, shown in Table 1, represent aggregated annual fixed charges associated with the source size combination, while the unit source and distribution costs are proportional to the quantity of commodity or service provided by that combination. Minimum distribution $\left(t_{i j}\right)$ and unit source cost $\left(c_{k}\right)$ for each combination are obtained by minimizing

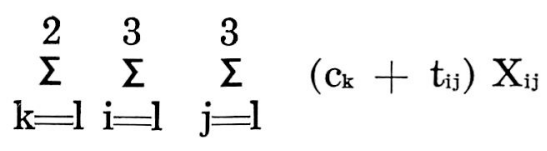

with a transportation algorithm.

After aggregating fixed and proportional costs for all combinations, it is observed that the global minimum cost is $\$ 17.10$ and is achieved with combination $(2,2,0)$. Source size 2 , located at source location 1 , ships 3 units to demand locations 1 and 3 while the same size source located at source location 2 ships 6 units to demand location 2.

To compare the Chern and Polopolus procedure with the source location cost-sequencing model, both models were applied to the above problem. The results are shown in Table 2 . The single location solution, obtained with the Chern and Polopolus model, involves placement of two large sources at source location 2. Whereas, the two-location solution includes a small source at location 1 and a small and a large source at location 2. The least-cost solution involves the two large sources at location 2-total cost of this organization is $\$ 17.40, \$ .30$ greater than the global minimum. The optimal solution resolved with the source location cost-sequencing model includes two large sources-one at source location 1 , the other at source location 2. The total cost of this organization is $\$ 17.10$, the global minimum.

\section{Numerical Application}

The source location cost-sequencing model was applied to resolve optimum regional cotton ginning industry organization in a portion of the Rio Grande River Valley (Figure 2). More efficient techniques of assembling cotton from farms to gin plants, as well as recently developed high capacity processing plants, have provided impetus for producer- 
TABLE 1.

Enumeration of Combinations for Numerical Example

\begin{tabular}{cccc}
\hline $\begin{array}{c}\text { Combinations of Two } \\
\text { Source Sizes At } \\
\text { Three Locations }\end{array}$ & $\begin{array}{c}\text { Source Fixed } \\
\text { Charge } \\
\left(f_{\mathrm{k}}\right)\end{array}$ & $\begin{array}{c}\text { Total Unit Source } \\
\text { and Distribution Cost } \\
\left(\mathrm{c}_{\mathrm{k}}+\mathrm{t}_{\mathrm{1}}\right)\end{array}$ & Total Cost \\
\hline$(1,1,1)$ & 6 & 14.30 & 20.30 \\
$(2,2,0)$ & 6 & 11.10 & $17.10^{*}$ \\
$(2,0,2)$ & 6 & 11.70 & 17.70 \\
$(0,2,2)$ & 6 & 11.25 & 17.25 \\
$(1,1,2)$ & 7 & 13.30 & 20.30 \\
$(1,2,1)$ & 7 & 12.60 & 19.60 \\
$(2,1,1)$ & 7 & 12.80 & 19.80 \\
$(2,2,1)$ & 8 & 11.10 & 20.30 \\
$(2,1,2)$ & 8 & 12.30 & 20.10 \\
$(1,2,2)$ & 8 & 12.10 & 20.10 \\
$(2,2,2)$ & 9 & 11.10 & \\
\hline
\end{tabular}

*denote optimum solution

owned cotton ginning cooperatives to examine potential cost savings of this new technology [4].

The objective was to determine the number, size and location of cotton gins which minimized total cost of processing and assembly. The empirical characteristics of the gin location problem were analogous to those outlined in the mathematical representation of the problem section. Although the gin location problem required consideration of assembly cost rather than distribution cost, the essential nature of the problem was not altered.

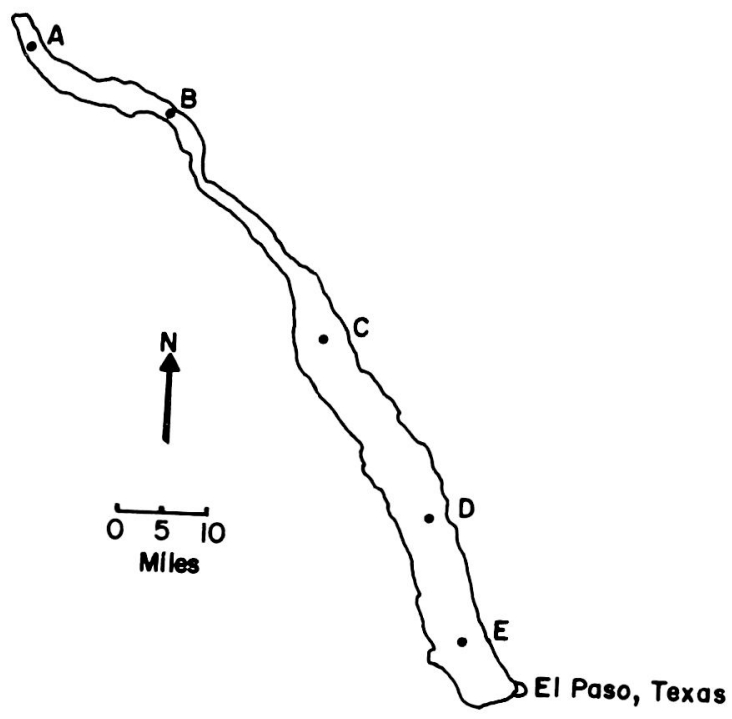

Figure 2. Potential Plant Locations, Rio Grande Valley 
TABLE 2

Comparison of Solutions Obtained with Chern-Polopolus Model and the Source Location Cost-Sequencing Model.

Chern-Polopolus Model

Source Location Cost-Sequencing Model

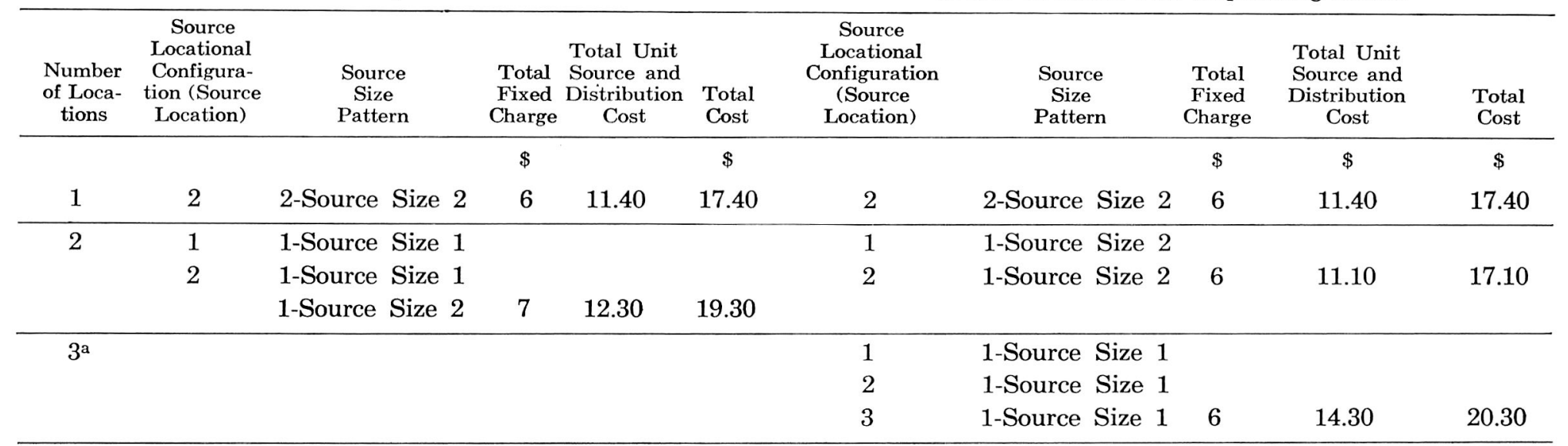

aThree location solution is identical to the two location solution because the locational figuration is not altered by the addition of a location. 
Gin plant size, or rate of plant output, is directly related to the number of gin stands within a plant; therefore, a one-gin-stand plant is capable of processing one-half the quantity per time period of a twogin-stand plant, etc. ${ }^{7}$ Manufacturers revealed that only five plant sizes $(\mathrm{P}=5)$ were technologically and commercially available. Because of the limited number of available plant sizes, the long-run plant function is discontinuous; that is, the long-run function is similar to that shown in Figure 1.

Based on zoning laws, location of transportation arteries or accessibility, projected urban developments and concentration of cotton production, twelve potential gin plant locations were selected $(\mathrm{N}=12)$. Existing plant locations were considered as potential plant sites only if the selection criteria were not violated.

Using Agricultural Stabilization and Conservation Service aerial photos and farmers' production data, the region was segmented into 139 production origins $(\mathrm{M}=139)$. With this data, a $139 \times 12$ matrix was constructed that related the quantity of cotton at each farm and distance between each farm and potential gin plant location. Unit-mile assembly cost between each farm and potential gin plant site was calculated with a previously estimated assembly cost function.

\section{Results}

The optimal plant size and locational configuration for a range of one through four locations is shown in Table 3 and Figure 2. Accomplishment of the developed model's initial step reveals that regional production is most efficiently processed with a 24- and 32-bale per hour plant, incurring a total plant cost of $\$ 797,186$ (Table 3 ). The overall least-cost solution involves locating these plants at sites C and D (Figure 2). This optimal locational configuration is obtained through accomplishment of Step 2.

The empirically determined locational pattern corresponds to the optimum configuration one would predict. That is, the overall least-cost plant locational configuration is attained by locating the plants in the most intensive production areas with some compensation for locational pulls of adjacent areas.

It is of interest to note that system costs behave as expected; that is, as the number of activated plants increase, total assembly costs decrease while total gin plant costs increase (Table 3). For the three location solution, assembly costs decrease $\$ 5,423$ relative to the two location solution; whereas, plant costs increase by $\$ 131,502$. A comparison of the three and four location solutions show similar cost behavior.

The Chern and Polopolus model was applied to the above problem so that its solution might be compared with the source location cost-sequencing model. The Chern and Polopolus model's solution involved a 16and a 40-bale per hour gin plant at $\mathrm{C}$ and $\mathrm{D}$ locations, respectively. The total cost of this organization was $\$ 1,018,211-\$ 9,783$ more than the source location cost-sequencing model's solution. 
TABLE 3.

Optimal Plant Size and Plant Location Configuration with Associated Plant and Transportation Cost for 1 Through 4 Plant Locations.

\begin{tabular}{|c|c|c|c|c|c|}
\hline $\begin{array}{l}\text { Number } \\
\text { of } \\
\text { Locations }\end{array}$ & $\begin{array}{c}\text { Gin } \\
\text { Plant(s) } \\
\text { Location } \\
\text { Configuration }\end{array}$ & $\begin{array}{c}\text { Gin } \\
\text { Plant Size(s) } \\
\text { Bale/Hour } \\
\text { Capacity }\end{array}$ & $\begin{array}{l}\text { Total Gin } \\
\text { Plant Cost } \\
(\$)\end{array}$ & $\begin{array}{c}\text { Total } \\
\text { Assembly Cost } \\
(\$)\end{array}$ & $\underset{(\$)}{\text { Total Cost }}$ \\
\hline 1 & $\mathrm{D}$ & $\begin{array}{l}24 \\
32\end{array}$ & 797,186 & 224,624 & $1,021,810$ \\
\hline 2 & $\begin{array}{l}\mathrm{C} \\
\mathrm{D}\end{array}$ & $\begin{array}{l}24 \\
32\end{array}$ & 797,186 & 211,242 & $1,008,428$ \\
\hline 3 & $\begin{array}{l}\text { B } \\
\text { C } \\
\text { E }\end{array}$ & $\begin{array}{r}8 \\
24 \\
32\end{array}$ & 928,688 & 205,819 & $1,134,507$ \\
\hline 4 & $\begin{array}{l}\text { A } \\
\text { B } \\
\text { C } \\
\text { E }\end{array}$ & $\begin{array}{r}8 \\
8 \\
16 \\
32\end{array}$ & $1,042,482$ & 204,628 & $1,247,110$ \\
\hline
\end{tabular}




\section{Summary}

The source location cost-sequencing model permits inclusion of a discontinuous long-run plant cost function, fixed charges and plant economies of scale. In addition, the model accommodates a heterogeneous spatial density of supply or demand. The developed model enables the researcher to incorporate additional realism, thus enhancing the value of the research product.

The source location cost-sequencing model does not guarantee a global minimum, since simultaneous variation is not attained in all problem dimensions. However, the addressed locational problem is not directly solvable given existing mathematical tools and constraints on computer time; thus, the developed procedure represents a positive contribution to empirical locational analysis.

\section{FOOTNOTES}

IA long-run plant cost function is comprised of a family of short-run functions, and, in a theoretical extreme, the long-run function becomes continuous. An early Scandinavian economist disputed the notion of a continuous long-run plant cost function. More recently, Chamberlin [2] and Brems [1] have given additional credence to the discontinuous cost function concept.

2 An empiricial short-run cost function showing constant marginal cost conflicts with economic theory's U-shaped function; however, this is reconciled by introduction of a rate dimension. A plant operating at its optimum output rate would be expected to incur constant marginal cost and accordingly give rise to linear total cost function. John Johnston suggested this form as most plausiable by accumulating empirical evidence [5].

${ }^{3}$ The mixed integer code available with International Business Machines Corporation's MPSX system is an example of the current generation of available codes.

4 If costs vary with plant location, this can be included by making alterations in the transportation matrix. This may be accomplished by adding to each column of the transportation cost matrix that additional unit cost associated with that particular location.

5This algorithm was implemented in APL/ 360. The algorithm enumerated plant cost associated with all plant size combinations capable of processing area production. In an applied case, involving five plant cost functions, 199 of the plant size combinations were capable of processing area production. These calculations were executed in approximately three seconds.

${ }^{6}$ The transportation code was developed by Dr. V. Srinivasan, Graduate School of Management, University of Rochester, Rochester, New York. This code was capable of solving a $100 \times 100$ transportation problem in approximately five seconds of computer time. The code was programmed to calculate transportation cost associated with locating each subset's least-cost plant size pattern among all combinations of potential locations. For example, locating four plants among eight potential locations would require ${ }_{8} \mathrm{C}_{4}=70$ separate solutions which would require less than six minutes of computer execution time. In the applied case, the overall least-cost solution always involved the overall optimum plant size pattern; therefore, attention was focused on optimally locating this plant size pattern. This substantially reduced computer time requirements.

7Separation of cotton lint from seed is accomplished by the gin stand which is the basis of plant output. All auxiliary gin plant equipment is designed to accomodate the gin stand operating at its optimal rate of output. Plant size or rate of output is directly related to the number of gin stands within the plant.

\section{REFERENCES}

[1] Brems, Hans, "A Discontinuous Cost Function," American Economic Review, Volume 42, 1952.

[2] Chamberlin, Edward H., "Proportionality, Divisibility and Economies of Scale," Quarterly Journal of Economics, Vol. 62, 1947.

[3] Chern, Wen-Shyong and Leo Polopolus, "Discontinuous Plant Cost Function and a Modification of the Stollsteimer Location
Model," American Journal of Agricultural Economics, Vol. 52, November 1970.

[4] Fuller, Stephen W. and Monty Washburn, Centralized Cotton Ginning: A Locational Analysis, New Mexico Agricultural Experiment Station Research Bulletin 646, September 1975.

[5] Johnston, John, Statistical Cost Analysis, McGraw-Hill Book Company, 1960. 